\title{
Patients' Perceptions of Informed Consent for Surgical Procedures in Northern Ireland: A Retrospective Survey
}

\author{
Heather Shannon ${ }^{1}$, Tricia Scott ${ }^{2}$ \\ ${ }^{1}$ MSc Nursing Student, Royal College of Nursing Institute, UK; ${ }^{2}$ MSc Nursing Research Dissertation \\ Supervisor, Royal College of Nursing Institute, UK
}

\begin{abstract}
Consent for surgical procedures is in the public domain following the Bristol and Liverpool enquiries [Department of Health, 2001a; House of Commons, 2001]. A legal and ethical principle exists whereby consent must be obtained before commencing a physical examination, starting treatment or physical investigation, or providing care. Non-compliance with this requirement is treated most seriously and professionals who choose to do otherwise risk investigation by the relevant regulatory body and/or legal proceedings. Guidance for health and social care professionals, including students, relates specifically to physical interventions on living individuals. The following research investigated patient satisfaction with the process of declaring informed consent prior to surgery. In 2006, a retrospective descriptive survey of a random sample of 200 patients two months following surgery was conducted in a local hospital in Northern Ireland. Data analysis generated frequencies and percentages using the Statistical Package for the Social Sciences (SPSS). Results suggested that the majority of respondents expressed satisfaction with the amount of information they had received, and most preferred to receive information from a mixture of doctors and
\end{abstract}

Correspondence to: Heather Shannon, Clinical Risk Manager, Risk Management Department, Health and Care Centre, 39 Regent Street, Newtownards, Co Down, Northern Ireland, UK. E-mail: heather. shannon@setrust.hscni.net nurses. The majority wanted the same amount of information, though there was a significant number who wanted more information. The importance of ensuring the patient receives adequate information prior to surgery/procedure is imperative if the health service is to offer transparency in surgical service provision in line with government guidelines.

Key words: informed consent; surgery; descriptive survey; surgeon; nurse; anaesthetist; Northern Ireland

\section{SUMMARY}

\section{What is already known about this topic}

In the United Kingdom, a legal and ethical principle exists, whereby consent must be obtained before commencing an examination, starting treatment or physical investigation, or providing care. While much has been written by professionals for professionals, there are few published papers on patient satisfaction with the informed consent process.

\section{What this paper adds}

This paper contributes to health care knowledge by providing a purposefully designed tool to establish patients' perceptions regarding the amount and nature of information given by nurses, surgeons and anaesthetists to enable the patient to provide informed consent prior to surgery/day procedure. Also, the 
results suggest the majority of patients do not want more information prior to surgical procedures; however, there is a small but significant group who would like more information prior to surgery/day procedure.

\section{INTRODUCTION}

Since April 2004 it has been mandatory in Northern Ireland to apply the principles of good practice in consent [Department of Health Social Services and Public Safety, 2003a, b, c]. Previously, there appeared to be significant variation in how the principles contained in the documents were applied, providing the rationale to investigate the current position in the selected Trust.

\section{BACKGROUND}

The NHS Plan [Department of Health, 2000] promised a review of the consent process due to its high public profile following the Bristol enquiry [DOH, 2001a] and the Liverpool enquiry [House of Commons, 2001], the outcome of which led to a number of recommendations. The government responded by publishing the Good Practice in Consent document [DOH, 2001b; DHSSPS, 2003a, b]. These recommendations are reflected in the Children's Heart Federation guide to care standards [Children's Heart Federation, 2001]. A Code of Practice was introduced with regard to the conduct of postmortems [DOH, 2003a], whilst the Human Tissue Act [DOH, 2004] and the Import and Export of Body Parts [DOH, 2003b] set clear limitations on the retention of organs and tissues for research following postmortem procedure.

The most recent government guidance regarding consent in Northern Ireland is the Reference Guide to Consent and Examination, Treatment or Care [DHSSPS, 2003a] advising:

'It is a general legal and ethical principle that valid consent must be obtained before commencing an examination, starting treatment or physical investigation, or providing personal care' ( $p .1)$.

Further, the HPSS Good Practice in Consent Handbook [DHSSPS, 2003b] reinforces the statutory responsibility of health professionals to safeguard the interests of their patients and contribute to a more transparent service through compliance with the informed consent procedure.

Various health databases were searched covering the last 10 years including Cochrane, CINAHL, Royal
College of Nursing, British Nursing Index, EBSCOhost, PubMed and MEDLINE. The following search terms were explored, 'informed consent', 'consent', 'informed patient consent', 'patient's perception of informed consent' and 'informed consent for treatment'. Most of the documents used were, naturally, written by professionals for professionals about professionals; there was little to find about patient satisfaction with the informed consent process. A range of statutory health policy literature was identified, which included the Consent Reference Guide [DHSSPS, 2003a], Quality Standards for Health and Social Care [DHSSPS, 2006], professional guidelines from the General Medical Council [GMC, 1998, 2006], and Nursing and Midwifery Council [NMC, 2004, 2005]. Of national significance, the Janine Murtagh Review [Regulation and Quality Improvement Authority, 2005] highlighted problems with the consent process from the patient's perspective and suggested regional auditing of the process.

Two journal articles reported survey research of aspects of patient satisfaction with the informed consent process. Howlader et al [2004] conducted a survey of 100 cardiac surgery patients, prior to discharge, in a hospital in England to ascertain opinion on the informed consent process. The design of the research instrument was unique to cardiac surgery and was therefore not readily transferable to other disciplines. Chan et al [2005] explored informed consent prior to blood transfusion using a postal survey in Canada, identifying a need to improve risk communication. Again the instrument was highly complex and not readily transferable to other contexts.

A range of journal articles discussed the subject of informed consent from a non-empirical anecdotal perspective. Waisel and Troug [1997] debated legal duty versus ethical obligation using cases from 1957 onwards. Dalla-Vargia et al [2001] discussed the historical aspects of consent, which stems from the philosophers and physicians of ancient times when it appeared that informed request was used as well as informed consent. This was perceived as similar to the modern concept of defensive medicine, in that the patient had to request treatment so that the provider of the treatment was not held responsible should something go wrong. O’Neill [2003] considered limitations of consent claiming that 'wholly specific consent is an illusion' (p. 4). Laing and McIntosh [2004] highlighted difficulties related to the time-consuming nature of the informed consent process for neonatal screening in Scotland by posing the question, 'Does every procedure in hospital or general practice now have to be covered by a signed consent form?' (p. 659). Pennels [2001] 
discussed legal issues arguing that it should be sufficient to record consent in the patient's notes, as any treatment or discussion with the patient should be documented according to the NMC guidelines on records and record keeping [NMC, 2005]. Bhutta [2004] explored consent in the research domain advising that it is 'a fundamental pre-requisite for conducting research' (p. 772). Bhutta's paper considers informed consent for research in developing nations; however, parallels exist in the West for individuals who do not always understand what is being asked of them, or feel they have no choice but to comply.

\section{THE STUDY}

\section{Aim}

The aim of the investigation was to establish patients' perceptions regarding the amount and nature of information given by nurses, surgeons and anaesthetists to enable the patient to provide informed consent prior to surgery/day procedure. There was no pre-conceived theory and the questionnaire was designed to ask factual questions to obtain nominal data that would generate descriptive statistics.

\section{Methodology}

The positivist research paradigm was selected to determine, by objective empirical systematic measures, the factual nature of the phenomenon. This clear epistemological and ontological position suggested that the use of a descriptive survey would facilitate the collection of relevant factual data that indicated the amount and type of information given to patients during the consent process [Abbott and Sapsford, 1998]. Polit and Beck [2004] explained the process of positivist quantitative research as a logical progression through a pre-specified plan of action that is designed to minimise bias and coercion.

\section{Design}

A retrospective descriptive postal survey gathered statistical data on aspects of the informed consent procedure from a representative sample of people who had undergone surgery/day procedure two months previously. In addition to demographic data, it was important to establish what preferences patients had about the amount and type of information provided to them. The study was conducted between February 2006 and January 2007, and data collection occurred during September and
October 2006. In line with the Northern Ireland research governance framework [DHSSPS, 2002], the proposal was approved by the Local Research Ethics Committee (LREC) and Office for Research Ethics Committees in Northern Ireland (ORECNI). Also, the research was discussed with the Director of Nursing, and a memo sent to lead clinicians and managers. In response to the recommendations of the Murtagh review [RQIA, 2005], research funding was supported by the local HPSS Trust.

\section{Sample}

During the period 1 May to 30 June 2006, the Theatre/ Day Procedure Unit operating list provided 1779 possible respondents. Using a probability frame, a random sample of 200 individuals was obtained, which was deemed to be a manageable sample within the timeframe available, and was representative of the population of 1779 people who had attended the Theatre/Day Procedure Unit.

The sample inclusion criteria concerned all patients who attended the Theatre/Day Procedure Unit between 1st May and 30th June 2006. No specific exclusion criteria were identified because Dental and Maternity patients were automatically excluded as they were not classed as surgical patients. Furthermore, paediatric patients were not identified within the exclusion criteria as there was no paediatric surgical service provided in the Trust.

The timeliness of data collection was critical because many industries and services were reduced during the 'Twelfth Fortnight', the two-week holiday period around 12th July in Northern Ireland. Each potential respondent was sent a covering letter, questionnaire and stamped addressed envelope for return of the completed questionnaire.

\section{Data collection instrument}

A purposefully designed self-completed postal questionnaire consisting of five sections was devised. Section 1 contained general questions about the consent form used prior to surgery. Section 2 contained three identical sections to obtain the type of information given by the nurse, surgeon and anaesthetist, for example, what happens during surgery, the type of dressings required or complications of surgery. Section 3 contained the respondent's preference and demographic questions (Figure 1 demonstrates the questionnaire used).

\section{Ethics}

The overarching principle for nurse researchers is to maintain the unique trusting relationship with patients; 


\begin{tabular}{|c|c|}
\hline THE CONSENT FORM & \\
\hline 1) Did you sign a consent form? & Yes/No/NA \\
\hline $\begin{array}{l}\text { 2) Who explained the consent form to you: } \\
\text { a) Doctor (surgeon or anaesthetist) } \\
\text { b) Nurse }\end{array}$ & $\begin{array}{l}\text { Yes/No/NA } \\
\text { Yes/No/NA }\end{array}$ \\
\hline 3) Were you given a copy of the signed consent form? & Yes/No/NA \\
\hline $\begin{array}{l}\text { 4) Did you expect to receive a copy of the signed consent } \\
\text { form? }\end{array}$ & Yes/No/NA \\
\hline $\begin{array}{l}\text { 5) Did you sign the consent form when you were at an } \\
\text { outpatient's appointment? }\end{array}$ & Yes/No/NA \\
\hline $\begin{array}{l}\text { 6) If yes, did you confirm you still wanted to proceed with } \\
\text { the surgery/procedure when you were admitted to the } \\
\text { ward? }\end{array}$ & Yes/No/NA \\
\hline $\begin{array}{l}\text { 7) Did you sign the consent form more than } 2 \text { weeks } \\
\text { before the surgery/procedure was done? }\end{array}$ & Yes/No/NA \\
\hline ASSESSMENT BEFORE YOUR SURGERY/PROCEDURE & \\
\hline THE NURSE & \\
\hline $\begin{array}{l}\text { 8) Did you attend a pre-assessment clinic conducted by a } \\
\text { nurse? }\end{array}$ & Yes/No/NA \\
\hline $\begin{array}{l}\text { 9) Were you contacted by telephone by a nurse prior to } \\
\text { admission? }\end{array}$ & Yes/No/NA \\
\hline $\begin{array}{l}\text { 10) Did you receive information about the } \\
\text { surgery/procedure to be carried out regarding: }\end{array}$ & Yes/No/NA \\
\hline a) the length of stay in hospital, & Yes/No/NA \\
\hline b) what happens during the surgery/procedure, & Yes/No/NA \\
\hline $\begin{array}{l}\text { c) what to expect after the surgery/procedure, for example } \\
\text { pain level, }\end{array}$ & Yes/No/NA \\
\hline d) driving after the surgery/procedure, & Yes/No/NA \\
\hline e) if a review appointment would be arranged, & Yes/No/NA \\
\hline f) if any dressings would be needed, & Yes/No/NA \\
\hline $\begin{array}{l}\text { g) what could go wrong, for example complications or } \\
\text { risks, }\end{array}$ & Yes/No/NA \\
\hline h) the reason for the surgery/procedure, & Yes/No/NA \\
\hline i) any alternatives if available, & Yes/No/NA \\
\hline j) a phone number to contact with any concerns? & Yes/No/NA \\
\hline 11) Did you understand the information provided? & Yes/No/NA \\
\hline 12) Did you have the opportunity to ask questions? & Yes/No/NA \\
\hline 13) If yes, were your questions answered? & Yes/No/NA \\
\hline
\end{tabular}

Figure 1. The questionnaire. 


\begin{tabular}{|l|l|}
\hline \multicolumn{2}{|l|}{ THE SURGEON } \\
\hline $\begin{array}{l}\text { 14) Did the surgeon provide information about the } \\
\text { procedure to be carried out, regarding: } \\
\text { a) the length of stay in hospital, }\end{array}$ & Yes/No/NA \\
b) what happens during the surgery/procedure, & Yes/No/NA \\
c) what to expect after the surgery/procedure, for example \\
pain level, & Yes/No/NA \\
d) driving after the surgery/procedure, & \\
e) if a review appointment would be arranged, & Yes/No/NA \\
f) if any dressings would be needed, & Yes/No/NA \\
g) what could go wrong, for example complications or risks, & Yes/No/NA \\
h) the reason for the surgery/procedure, & Yes/No/NA \\
i) any alternatives if available, & Yes/No/NA \\
j) a phone number to contact with any concerns? & Yes/No/NA \\
\hline 15) Did you understand the information provided? & Yes/No/NA \\
\hline 16) Did you have the opportunity to ask questions? & Yes/No/NA \\
\hline 17) If yes, were your questions answered? & Yes/No/NA \\
\hline
\end{tabular}

\section{THE ANAESTHETIST}

18) Did the anaesthetist provide information about the procedure to be carried out regarding:

a) the length of stay in hospital,

Yes/No/NA

b) what happens during the surgery/procedure,

c) what to expect after the surgery/procedure, for example pain level,

d) driving after the surgery/procedure,

e) if a review appointment would be arranged,

f) if any dressings would be needed,

Yes/No/NA

Yes/No/NA

Yes/No/NA

Yes/No/NA

Yes/No/NA

g) what could go wrong, for example complications or risks,

Yes/No/NA

h) the reason for the surgery/procedure,

Yes/No/NA

i) any alternatives if available,

Yes/No/NA

j) a phone number to contact with any concerns?

Yes/No/NA

\begin{tabular}{l|l|l} 
19) Did you understand the information provided? & Yes/No/NA
\end{tabular}

20) Did you have the opportunity to ask questions?

21) If yes, were your questions answered?

Yes/No/NA

Yes/No/NA

Figure 1. Continued. 


\begin{tabular}{|l|l|}
\hline \multicolumn{2}{|l|}{ GENERAL QUESTIONS } \\
\hline 22) Would you prefer to receive information from a nurse? & Yes/No/NA \\
\hline $\begin{array}{l}\text { 23) Would you prefer to receive information from a doctor } \\
\text { (surgeon or anaesthetist)? }\end{array}$ & Yes/No/NA \\
\hline $\begin{array}{l}\text { 24) Would you prefer to receive information from a } \\
\text { mixture of both nurses and doctors? }\end{array}$ & Yes/No/NA \\
\hline 25) Was your surgery/procedure planned in advance? & Yes/No/NA \\
\hline 26) Was your surgery/procedure an emergency? Yes/No/NA & \\
\hline $\begin{array}{l}\text { 27) Was your surgery/procedure planned and organised } \\
\text { from another hospital? }\end{array}$ & Yes/No/NA \\
\hline $\begin{array}{l}\text { 28) If you had to go through the same surgery/procedure } \\
\text { again would you like to know: }\end{array}$ & \\
\hline a) more & Yes/No/NA \\
b) less & Yes/No/NA \\
b) was a translated version of the consent form available? & Yes/No/NA \\
\hline c) the same? & Yes/No/NA \\
\hline 29) Are you male? $65+$ years & Yes/No \\
\hline b) $25-49$ years $50-64$ years & Yes/No \\
\hline 30) Are you female? & Yes/No \\
\hline 31) Which age group best describes you? & Yes/No \\
\hline
\end{tabular}

Figure 1. Continued.

hence, consideration was given to the following six ethical aspects: beneficence, non-maleficence, fidelity, justice, veracity and confidentiality [Parahoo, 2006]. Whilst there was no immediate benefit to respondents, disclosing deficiencies in the way informed consent is obtained strengthened the informed consent process. Although no risk of harm was anticipated, one respondent's relative expressed by telephone that her father had died one week prior to receiving the questionnaire. This telephone conversation required sensitivity, and subsequent checks revealed three other potential respondents whose names were withdrawn to avoid unnecessary distress.

\section{Data analysis}

A total of 131 questionnaires were returned, 29 were discarded either because the form had been spoiled $(n=11)$, consent had not been signed $(n=7)$, a substantial amount of the form was not completed $(n=5)$, the respondent stated they could not remember $(n=3)$, the respondent was under 18 years of age $(n=2)$ or the form arrived too late to be analysed $(n=1)$. This left a total of 102 completed questionnaires for analysis. Seven respondents declared that a consent form had not been signed prior to surgery though it was 


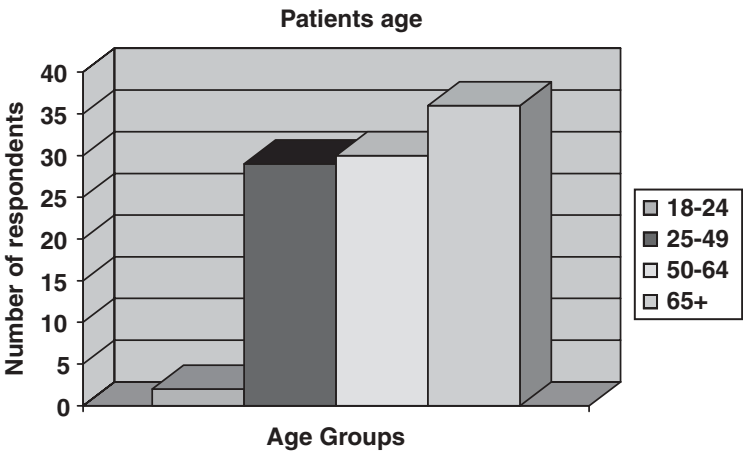

Figure 2. Age distribution.

presumed that names of persons recorded on the Theatre or DPU attendance database would have signed a consent form. Due to anonymity it was impossible to ascertain the reason though it is possible that these individuals may not have remembered signing, or the procedure may have been cancelled or postponed prior to signing. Two individuals were under 18 years of age (seven and six) and in the absence of a dedicated paediatric surgical service at the hospital it is surmised that these children were consented for minor operations under local anaesthetic such as wedge resection of ingrown toenail.

Demographics. The largest age category was $65+$, and there were almost twice as many females as males. Questions related to age attracted a high number of nonresponses, which suggests a multiple-choice approach to answering by ignoring the 'not applicable' option. Age distribution is presented in Figure 2. Gender-related questions (questions 29 and 30) were not fully answered perhaps due to the arrangement of the questions whereby the respondent was required to answer both. In fact, many only answered one of the two questions. In relation to question 29, 'are you male?' 31 answers were missing out of 71 responses; In relation to question 30, 'are you female?' 16 answers out of 86 responses were missing. Gender distribution is presented in Figure 3.

Comment on analysis: the consent form. In relation to the provision of an explanation of the surgical investigation/procedure by a doctor, $36.3 \%(n=37)$ did not answer the question. Similarly, $42.2 \%(n=43)$ did not answer the question regarding whether the nurse had explained the consent details for the surgical investigation/procedure. Again, responses lacked accuracy though no logical explanation can be offered for the high rate of omitted data. However, 101 out of 102 responded to question 3, confirming that they had been given a copy of the signed consent form. One hundred out of 102 replied to question 4 in that they had

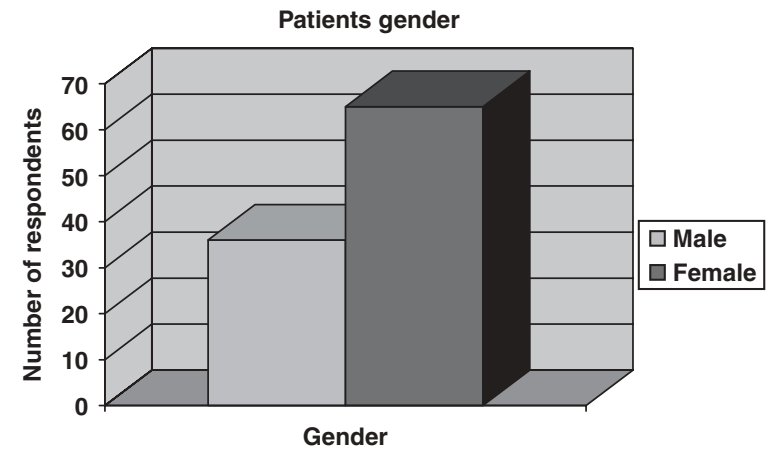

Figure 3. Gender distribution.

expected to receive a copy of the signed consent form. Furthermore, $32.7 \% \quad(n=33$ out of 101 responses) confirmed that they were given a copy of the consent form, and $29 \%$ ( $n=29$ of 100 responses) had expected to be given a copy. It would be interesting to ask if respondents were offered a copy as opposed to being given a copy to see if this altered the statistics. DHSSPS [2003a, b] guidance advises that patients should be 'offered' a copy of the consent form. This is an important issue to raise in that although the data tell us how many respondents were given or expected to receive a copy of the consent form, it does not tell us how many respondents were aware that they should be offered a copy.

In question 5 related to the signing of the consent form, $62.6 \%$ ( $n=62$ of 99 respondents) signed whilst attending the Out Patients Department. This was expected, because the hospital provided mainly elective surgery, whilst surgical emergencies required transfer to another Trust. There were also direct access clinics for General Practitioner referrals for endoscopy and patients attending these clinics would sign their consent form on admission to the Day Procedure Unit. Only $26.8 \%$ ( $n=26$ of 97 responses) of respondents declared that they had signed the consent form more than two weeks prior to the planned procedure. It is possible that individuals who signed more than two weeks in advance could have been waiting for inpatient operations such as hysterectomy, which would be organised well in advance of admission. Of the total, $74.1 \%$ ( $n=63$ of 85 respondents) confirmed their consent on admission. Usually the doctor asks whether the patient still wishes to proceed with the planned procedure: the doctor then signs and dates the consent form in the designated space. Again, it may be that these individuals did not recall confirming consent or that consent had not been confirmed earlier. While written consent evidencing a signature on the consent sheet remains 
valid, it is good practice to confirm consent if some time has elapsed since the form was originally signed. The patient has the right to withdraw consent at any time [DHSSPS, 2003a]; however, it is not clear whether or not this right is conveyed accurately to the patient.

Nurse-led pre-assessment. The Trust had two systems for nurse-led pre-assessment: telephone preassessment and face-to-face clinic appointment. The hospital used for this survey was part of a network of hospitals, providing theatre time for surgeons from other hospitals in an attempt to reduce surgical waiting times. Also, some hospitals had nurse-led pre-assessment clinics, so it is not surprising that $44 \%(n=44$ of 100 responses) confirmed that they had attended a nurse-led pre-assessment clinic, and $25.7 \% \quad(n=26$ of 101 responses) verified that they had been pre-assessed by telephone. As expected, the majority of surgery was planned $(90.2 \%, n=92)$ and only $5.9 \%(n=6)$ declared that their surgery was an emergency. As was also expected, $27.5 \%(n=28)$ of the respondents confirmed that surgery was planned elsewhere in keeping with the hospital surgical network. Therefore consent may have been obtained in another Trust with implications for variation in the process of obtaining informed consent.

Identical questions re: nurse/surgeon/anaesthetist. In Section 2 of the questionnaire, respondents were asked identical questions relating to the nurse, surgeon and anaesthetist. It is possible that 'not applicable' responses might mean that the patient simply was not seen by that practitioner, or that the practitioner did not complete the consent form with the patient. 'Yes' answers could mean that the patient was seen and informed by that practitioner. 'No' answers could mean that the patient was seen by that practitioner and did not receive the specified information from him/her, or that the patient did not see that practitioner and treated the answer 'no' in the same way as 'not applicable'. It is likely that all patients communicate with a nurse during their contact with the hospital, either at admission/ discharge, at clinics or at pre-assessment. Of the total, $95 \%$ ( $n=95$ of 100 responses) confirmed that they had understood the information about the procedure from the nurse, $88 \%$ ( $n=88$ of 100 responses) verified that they had been provided with an opportunity to ask questions and $86.5 \%(n=83)$ of 96 respondents answered that their questions were answered.

It is reasonable to assume that $86.3 \%(n=88)$ communicated with a nurse whilst $85.9 \% \quad(n=85$ of 99 respondents) confirmed that they understood the surgeon. An opportunity was provided to $81 \%(n=81$ of 100 responses) to ask the surgeon questions about the surgery/procedure and $84.4 \%$ ( $n=76$ of 90 responses) confirmed that their questions had been answered. The latter statement suggests that $79.4 \%(n=81)$ did communicate with a surgeon. However, this trend reduces significantly for the anaesthetist group in that $59.1 \%$ ( $n=55$ of 93 responses) answered they had been provided with an opportunity to ask the anaesthetist questions, and $56.2 \%$ ( $n=50$ of 89 responses) answered that their questions had been answered. This statement suggests that only just over $50 \%$ of anaesthetists and just over $75 \%$ of surgeons communicate consent issues with their patient prior to surgery. The above figures appear consistent with the existing referral system and type of surgery being performed. It is expected that most patients would communicate with a nurse; however, many, but not all, patients would communicate with a surgeon and significantly less would communicate with an anaesthetist.

Approximately $43.6 \% \quad(n=34$ of 78 responses $)$ answered that they did not want the information regarding consent to be given by a nurse, while only $16.7 \%$ ( $n=14$ of 84 responses) answered that they did not want information to be given by a doctor. The majority $(87.8 \%, n=86$ of 98 responses) stated their preference to receive consent information from a mixture of both nurse and doctor. It could be argued that persons aged over 65 may have been brought up in an era of greater medical paternalism with resulting patient compliance, whereby it was not deemed to be correct behaviour to disagree with or question the doctor.

When considered as a percentage of the total questionnaires received $(n=102), 75.5 \% \quad(n=77)$ expressed preference for the same amount of information if they were to experience the same surgery/procedure, whilst almost $22.5 \% \quad(n=23)$ confirmed that they would like more information. No one wanted less information; so overall this appears to demonstrate that the majority of patients were content with the level of information they received.

\section{DISCUSSION}

Limitations of survey research include non-response and reactivity, and these aspects were carefully considered when designing the questionnaire [Abbott and Sapsford, 1998; Strommel and Wills, 2004]. The selfreport survey had a number of limitations concerning, first, the nature of the information people were willing to give [Polit and Beck, 2004]. Second, given that the questions drew on historical events, what people remembered was uncertain so it is unclear whether 
questions were answered accurately [Strommel and Wills, 2004]. Wording of questions was very important in that the data obtained were descriptive of the people's experiences relating to informed consent. It could be argued that information obtained from a selfreport questionnaire may be unreliable or inaccurate because the researcher had no control over how and where the form was completed [Abbott and Sapsford, 1998].

\section{Actions taken to minimise identified limitations}

The use of specific wording was imperative to creating a questionnaire that was fit for purpose [McColl et al, 2001; Fink, 2006]. Critical readers provided constructive criticism before version nine was finalised and the cover letters and instruction sheets were piloted to ensure the data would be useful and meaningful [Oppenheim, 1992].

\section{Limitations}

It was striking to note that many respondents chose to treat specific questions in a multiple-choice fashion, although that was not how the questionnaire and instructions for completion were designed. It would be interesting to learn whether multiple-choice questions might have generated different and more meaningful data, i.e. a reduced volume of 'missing' data because respondents choose from a range of options instead of completing every question.

In some instances, there appeared to be a pattern forming where the answers to questions $14 \mathrm{a}-\mathrm{j}$ and $15-17$ (surgeon) were the same as those given for $18 \mathrm{a}-\mathrm{j}$ and 19-21 (anaesthetist). It may be that the surgeon and anaesthetist did provide the same information as part of a standardised format; however, it is also possible that respondents chose to answer identical questions in an identical way for ease of completion. Alternatively, they may not have remembered or differentiated between what was said by each practitioner. Questions $10 \mathrm{a}-\mathrm{j}$ and 11-13 (nurse) did not display the same pattern. It is possible that the questionnaire was too long, and people became bored, especially as the middle sections were identical. If the study were to be repeated, it may be more accurate to assess satisfaction strictly by profession, e.g. nurse, surgeon, anaesthetist; however, this would not resolve the problem of patients who needed to see two or all three of these professionals. Asking patients to complete 3 questionnaires would be excessive and is likely to result in responder fatigue [McColl et al, 2001].
Interviews might provide more detailed information, which would enable further research studies to become more focussed, though researcher bias is always a feature of this method.

\section{Comparison of results to other studies}

In the literature review, two research studies were identified, Howlader et al [2004] and Chan et al [2005] to be discussed in relation to the findings of this research. Comparison with the present research study is likely to be problematic due to the use of different instruments and patient groups. However, tentative comparison with aspects of the results is possible in appreciation that this is not a comparison of like with like.

Howlader et al [2004] studied 100 consecutive cardiac patients regarding patients' perceptions and recollections of the consent process concluding that the majority of patients confirmed they had received adequate information and did not want more. This is in keeping with the findings reported in the present study. Question 3 of Howlader et al [2004] was imported to question $28 \mathrm{a}-\mathrm{c}$ making tentative comparison possible. Howlader et al [2004] found 81 out of 100 respondents would like the same amount of information, 17 out of 100 wanted more information and two out of 100 wanted less information. In the current survey, $75.5 \%(n=77)$ wanted the same information, $22.5 \% \quad(n=23)$ wanted more information and no one wanted less information. Considering the results of both studies, it can be assumed that the majority of people appear to be content with the amount of information they received. In both studies, approximately $20 \%$ (17\% in Howlader et al [2004] compared to $22.5 \%$ in this study) of respondents would like more information. No other comparison is possible.

Chan et al [2005] conducted a postal survey regarding blood transfusion and consent, receiving a return of $51 \%$. Of those who returned the questionnaires, $80 \%$ recalled having a discussion regarding consent and signing the consent form. In the present study, only seven respondents stated that they did not sign a consent form but as information recall on the discussion was not sought no direct comparison could be made. Chan et al [2005] found $77 \%$ understood the discussion, which could be tentatively compared to the answers to questions about understanding the nurse, surgeon and anaesthetist, but it is difficult to draw meaningful comparisons because the current study was specific about which professional was involved. There may also be an opportunity for comparison regarding 
discussion of risk and surgery/anaesthetic alternatives, as questions regarding information received on both of these aspects were considered. Chan et al [2005] found that $44 \%$ did not recall discussing transfusion risks, and $88 \%$ did not recall discussing alternatives to donor blood. Figure 4 demonstrates a much higher level of discussion of risk in the present survey than Chan et al [2005] reported. In the present survey, only $17.6 \%$ $(n=18)$ answered 'no' to question $10 \mathrm{~g}$ about receiving information from the nurse about risks; only $19.6 \%$ $(n=20)$ answered they did not receive information about risks from the surgeon (question $14 \mathrm{~g}$ ); while $31.4 \%(n=32)$ stated they had not received information about risks from the anaesthetist (question $18 \mathrm{~g}$ ). Also in the current research, a higher number of positive answers were obtained by nurses (question 10i), surgeons (question 14i) and anaesthetists (question 18i), in terms of discussing alternatives. Figure 5 explains how professionals presented alternative options. Only $41.2 \%(n=42)$ answered that alternatives were not discussed by nurses, $38.2 \% \quad(n=39)$ answered that the surgeon did not discuss alternatives and $40.2 \% \quad(n=41)$ answered that the anaesthetist did not provide information about alternatives. Both Howlader et al [2004] and Chan et al [2005] suggest

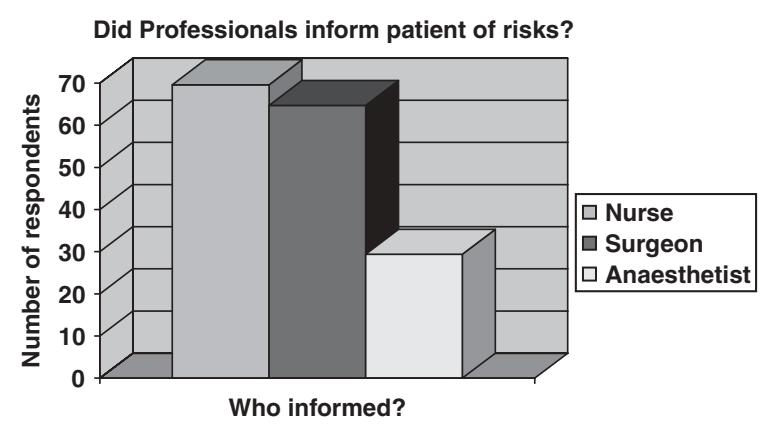

Figure 4. Giving information on risks.

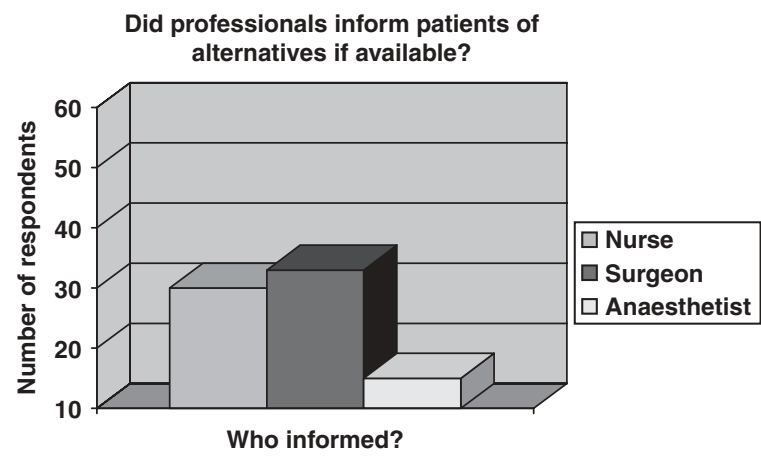

Figure 5. Giving information about alternative options. that patients' feel better informed if provided with written information in addition to the verbal discussion though the issue of written supplementary information did not form part of the current study, and therefore no comparison can be drawn. It remains important to consider that the above comments cannot compare like with like.

\section{Conclusions}

This study was necessarily small due to constraints of time and resource, a feature of the Masters Degree programme. However, a return of $51 \%$ usable questionnaires is deemed good [Abbott and Sapsford, 1998]. The results could be verified should it be replicated elsewhere to establish generalisability. Additionally, there is potential for this study to be used as a pilot for a larger study. Overall, the impression is that respondents were, in the main, satisfied with the amount of information they received, and understood the information. Findings from this research would contribute to the design of further research. In relation to question $28 \mathrm{a}$, regarding whether people would like more information, it would be useful to investigate what specific information patients would like more of. Thus, informing practice in relation to the provision of pre-operative information and providing an issue for more targeted research to gain insight into what specific areas of information deficiencies exist. By adapting the questionnaire to become profession-specific, questionnaires may yield more detailed data. Further research may help to explain the reasons as to why so many patients did not answer questions $32 \mathrm{a}$ and $32 \mathrm{~b}$ regarding interpreting services. It is not possible to comment on ethnic background because no questions were asked regarding this, making it impossible to know whether people did not want to declare themselves as foreign, or did not understand the question. Finally, there is scope for further research and implications for how preoperative care is organised to establish what deterred people from signing a consent form.

Aspects of professional practice that have been noted concern the need to ensure the patient is offered a copy of the consent form, and the requirement to make sure consent is confirmed if the form was signed in advance. This research addressed a gap in the literature, which indicated that patient's views regarding the consent process were rarely explored in empirical research papers, and drives home the importance of accurate and timely information giving, combining transparency and choice in the patient's surgical experience at a time when patients are most vulnerable. 


\section{REFERENCES}

Abbott P, Sapsford R. Research Methods for Nurses and the Caring Professions (2nd edn). Buckingham: Open University Press, 1998.

Bhutta ZA. Beyond informed consent. Bulletin of the World Health Organization 2004; 82(10): 771-778.

Chan T, Eckert K, Venesoen P, Leslie K, Chin-Yee I. Informed consenting to blood: what do patients remember? Transfusion Medicine 2005; 15(6): 461-466.

Children's Heart Federation. Children's Heart Services: A Guide to Care Standards; Guidelines for Paediatric Cardiac Services in the UK. Children's Heart Federation, 2001.

Dalla-Vargia P, Lascarates J, Skiadas P, Geranis-Papadatos T. Is informed consent in medicine a concept only of modern times? Journal of Medical Ethics 2001; 27(1): 59-61.

Department of Health. The NHS Plan: a Plan for Investment, a Plan for Reform. London: The Stationery Office (Cmnd 4818-I), 2000.

Department of Health. Learning from Bristol: the Report of the Public Inquiry into Children's Heart Surgery at the Bristol Royal Infirmary 1984-1995. London: The Stationery Office (Cmnd 5207) (Chairperson: I. Kennedy), 2001a.

Department of Health. Good Practice in Informed Consent Implementation Guide: Informed Consent to Examination or Treatment. London: DoH, 2001b.

Department of Health. Families and Post Mortems: a Code of Practice. London: DoH, 2003a.

Department of Health. The Import and Export of Human Body Parts and Tissue for Nontherapeutic Uses - a Code of Practice. London: DoH, 2003b.
Department of Health. Human Tissue Act. London: The Stationery Office, 2004.

Department of Health Social Services and Public Safety. Research Governance Framework for Health and Social Care. Belfast: DHSSPS, 2002.

Department of Health Social Services and Public Safety. Reference Guide to Consent for Examination, Treatment or Care. Belfast: DHSSPS, 2003a.

Department of Health Social Services and Public Safety. Good Practice in Consent. Consent for Examination, Treatment or Care: a Handbook for the HPSS. Belfast: DHSSPS, 2003b.

Department of Health Social Services and Public Safety. Good Practice in Consent. Belfast: DHSSPS (HSS (MD) 7/2003), 2003c.

Department of Health Social Services and Public Safety. The Quality Standards for Health and Social Care: Supporting Good Governance and Best Practice in the HPSS. Belfast: DHSSPS, 2006.

Fink A. How to Conduct Surveys: a Step-by-step Guide (3rd edn). Thousand Oaks: Sage, 2006.

General Medical Council. Seeking Patients' Consent: the Ethical Considerations. London: GMC, 1998.

General Medical Council. Good Medical Practice. London: GMC, 2006.

House of Commons. The Royal Liverpool Children's Inquiry Report. London: The Stationery Office (Chairman: M. Redfern), 2001.

Howlader MH, Dhanji A-R, Uppal R, Magee P, Wood AJ, Anyanwu AC. Patients' views of the informed consent process for adult cardiac surgery: questionnaire survey. Scandinavian Cardiovascular Journal 2004; 38(6): 363-368.
Laing IA, McIntosh N. Practicalities of informed consent. Lancet 2004; 364(9435): 659.

McColl E, Jacoby A, Thomas L, et al. Design and use of questionnaires: a review of best practice applicable to surveys of health service staff and patients. Health Technology Assessment 2001; 5(31): 1-255.

Nursing and Midwifery Council. The NMC Code of Professional Conduct: Standards for Conduct, Performance and Ethics. London: NMC, 2004.

Nursing and Midwifery Council. Guidelines for Records and Record Keeping. London: NMC, 2005.

O'Neill O. Some limits of informed consent. Journal of Medical Ethics 2003; 29(1): 4-7.

Oppenheim AN. Questionnaire Design, Interviewing and Attitude Measurement. New York: St Martin's Press, 1992.

Parahoo AK. Nursing Research: Principles, Process and Issues (2nd edn). Basingstoke: Macmillan Press Ltd, 2006.

Pennels C. Obtaining informed consent: the use of a consent form. Professional Nurse 2001; 16(10): 1433-1434.

Polit DF, Beck CT. Nursing Research: Principles and Methods (7th edn). Philadelphia: Lippincott Williams \& Wilkins, 2004.

Regulation and Quality Improvement Authority. Review of the Lessons Arising from the Death of Mrs Janine Murtagh: Quality Improvement Review. Belfast: RQIA, 2005.

Strommel M, Wills CE. Clinical Research: Concepts and Principles for Advanced Practice Nurses. Philadelphia: Lippincott Williams \& Wilkins, 2004.

Waisel DB, Troug RD. Informed consent. Anesthesiology 1997; 87(4): 968-978. 